This item was submitted to Loughborough's Institutional Repository (https://dspace.lboro.ac.uk/) by the author and is made available under the following Creative Commons Licence conditions.

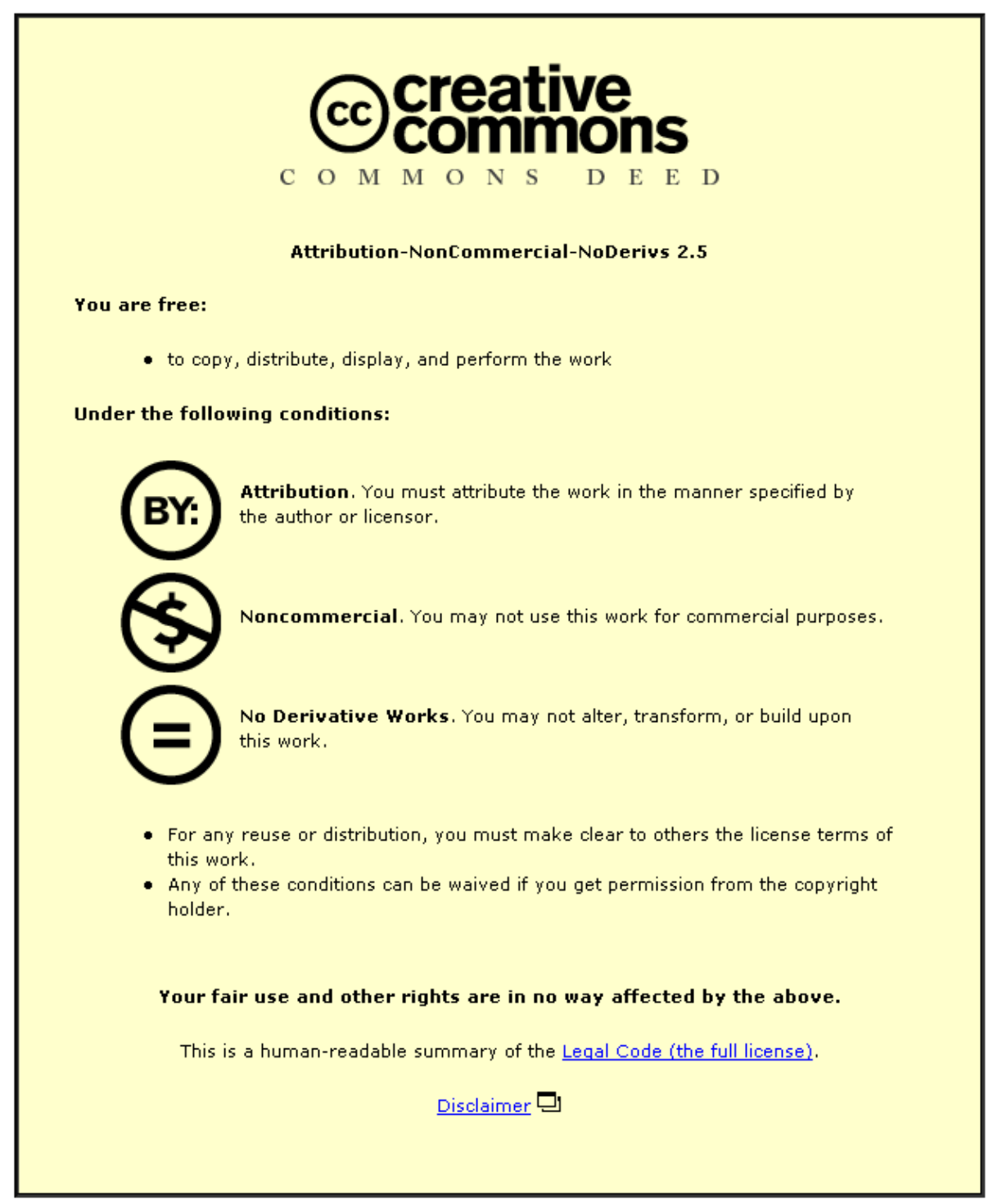

For the full text of this licence, please go to: http://creativecommons.org/licenses/by-nc-nd/2.5/ 


\title{
A Stakeholder-Based Analysis of the Benefits of Network Enabled
}

\section{Capability}

\author{
Elena Irina Neaga and Michael Henshaw \\ Engineering Systems of Systems Group \\ Department of Electrical and Electronic Engineering, \\ Loughborough University, Leicestershire, LE11 3TU, United Kingdom \\ E-mail: \{E.I.Neaga, M.J.d.Henshaw\}@lboro.ac.uk
}

\begin{abstract}
Realisation of the benefits sought from Network Enabled Capability (NEC) requires industry and UK Ministry of Defence (MoD) to work effectively together with a shared vision. Earlier studies have revealed disparate understandings of the NEC concept and a lack of agreement on its definition. Furthermore, although the benefits of NEC have been intuitively recognised, it is not clear that these benefits have been metricated in a fashion suitable to justify the investment needed in research and development for their realisation. This paper reports on a workshop involving military users and industrial systems engineers that sought to identify and prioritise the benefits of NEC through which NEC development may be assessed. It also draws on the outcomes of other interactive workshops on the perception of NEC by stakeholders organised within the framework of NECTISE research programme.
\end{abstract}

The motivation for this paper is to disseminate NEC benefits on which there is industry and user consensus to encourage the generation of meaningful measurements of NEC value in the future.

The outcomes have revealed considerable coherence between the stakeholder groups in recognition and priority of the benefits, although these benefits were all of an operational (military) nature. This indicates a good prospect for industry engagement in the NEC aspiration and metrics are now needed to measure the effectiveness of using NEC in different 
contexts such as military and industry. The benefits are also included in the impact of NEC on the systems engineering discipline, but in order to achieve them systems engineering may be required to change or adapt new practices.

\section{$1 \underline{\text { Introduction }}$}

The concept of Network Enabled Capability (NEC) was coined in the late 1990s, but there still remains some debate from both theoretical and practical perspectives regarding key aspects. Theoretical attempts to define NEC are mainly context dependent and whilst the benefits of better information sharing that NEC is supposed to deliver are generally accepted from an intuitive point of view, there seems to be little by way of metrics (quantified proof) to underpin balance of investment decisions regarding NEC research, development and procurement. The early lack of clarity surrounding NEC has been problematic; Blair et. al. ${ }^{1}$ have attributed lack of progress in realisation of the UK NEC aspiration to the absence of a clear definition and Quintana's ${ }^{2}$ findings through stakeholder interviews indicated that industry was generally unclear on how to engage with the NEC challenge.

Although there remain differences in the descriptions of NEC, the benefits sought are now being realised in a practical sense ${ }^{3}$ and this is providing greater clarity of the route to their achievement. This is, at least in part, due to the growing emphasis among all stakeholders on 'capability' as opposed to 'networks'. In this paper, we consider the output of a joint workshop, between senior systems engineers from industry and military and civilian members of the UK MoD, to identify and prioritise the benefits of NEC. We relate these to both the UK MoD's benefits chain ${ }^{4}$ and a model of NEC-readiness themes, derived in the NECTISE (Network Enabled Capability Through Innovative Systems Engineering) research programme. 
Our purpose in conducting this work has been to test the degree to which industry and MoD share a view of NEC benefits and thereby to assist the development of a concept of NEC upon which they may agree, derived from a systems perspective. The work reported herein concerns the first of these objectives.

\subsection{NEC Contrasts and Affinities}

In 2003, the UK MoD provided the following definition of $\mathrm{NEC}^{5}$ :

...the enhancement of capability through the effective linkage of platforms and people through a network.

But later, in 2005, it stated in JSP $777^{6}$ that "Our understanding of NEC will continue to develop, so it is important not to constrain the future direction of NEC by an overlyrestrictive definition". In general, authors from a variety of backgrounds have chosen to describe, rather than define, the concept, mainly relying on projected and desired outcomes.

Through a comprehensive study, based on stakeholder interviews, Quintana ${ }^{7}$ concluded that "NEC as a concept is achievable if the capability (and the capability road map) is carefully defined, if acquisition is sufficiently agile to respond to advances in the commercial sector and if appropriate balance is given to all Defence Lines of Development. (DLoDs)"

Alberts and Hayes ${ }^{8}$ have developed a conceptual framework for NCW (Network Centric Warfare) through which its features are related to individual sense making and decision making. They represent this with a set of variables that pertain to team, group, or organizational sense making and decision making capabilities. These team, group, and organizational attributes include the degree to which (1) information is shared and (2) shared awareness is achieved. These variables are at the heart of the collaborative processes and selfsynchronizing behaviours that NCW seeks to exploit. 
Although conceptually NEC, NCW and NCO (Network Centric Operation) are similar, in that they concern the enhancement of military operations through effective networking strategies, some authors ${ }^{9,10,11,12}$ have described significant differences between the USoriginated concepts of NCW versus the UK adaptation of NCW as NEC:

- NCW is considered to be resource driven, whereas NEC is resource limited.

- NCW considers the network to be the primary driver, whereas NEC views the network as an enabler.

- $\mathrm{NCW}$ is considered a doctrine, whereas NEC is considered part of a gradual improvement or transformation in force effectiveness.

- $\mathrm{NCW}$ is a planned and structured development of technology roll-out, whereas NEC is expected to evolve through networking battlefield entities.

- NCW is limited, by definition, to warfare, whereas NEC is expected to be applied more widely to Operations Other Than War (OOTW) as well as in industry. However, it is noted that in recent times the wider interpretation has started to be applied in NCW.

- $\quad \mathrm{NCO}$ is used in USA and it is overcoming NCW limitations.

NEC is also an applied "system of systems" concept and, as such, it possesses emergent behaviours that are unattainable by any of the individual systems making up the NEC when considered in isolation. Emergent behaviour is a key characteristic of system of systems (SoS) that can have positive or negative consequences depending of the different factors and contexts. The NECTISE core research team's description of NEC, formulated from those above and elsewhere, is that ${ }^{13}$ :

NEC is the enhancement, or realisation, of military capability achieved through effective information sharing between geographically and/or temporally distributed sensors, decision makers, effectors, and support services. 
The NEC benefits must be assessed in terms of enhancement of, or creation of new, capabilities that are related to changes (improvements) in information sharing and effective utilisation.

Generally, NEC leads to better shared situational awareness of collaborating entities, which reduces or mitigates the risk of errors, and to greater agility in the prosecution of missions. Blair et al. ${ }^{14}$ have approached NEC and its challenges as "a complex human activity system of systems, analysis of which cannot rely on purely traditional reductionist engineering approaches, requiring instead a soft-systems engineering approach." NEC can also be considered as a long-term change programme and in the near future the communications systems, information systems, operational procedures and knowledge will effectively work together in an improved approach to UK military operations.

NECTISE was a collaborative research programme between BAE Systems and ten UK universities. Its main purpose was to create and develop the systems engineering approaches, tools and technologies needed to effectively meet the challenges of NEC (http://www.nectise.com). This programme addressed the question "are you ready for NEC?" from multiple interrelated perspectives that can be grouped under the two headings of operational (implying military operations) and organisational (implying the defence acquisition and supply chain activities). Work within this programme indicated that there were differences in views between (and within) industry, MoD and the armed services with respect to NEC and certainly in terms of expectations. Therefore, investigations were required to understand these differences and an empirical study was undertaken to record and analyse the benefits sought of NEC by the various stakeholders. The articulation of these benefits will enable appropriate metrics to be developed that provide a means through which stakeholders may agree and measure the improvements attributable to NEC. 
The paper begins with presentation of a model of NEC-readiness and relates this to the NEC benefits chain ${ }^{15}$. The views of stakeholders, as expressed at a benefits workshop, are presented and from these we present the prioritised NEC benefits and draw some initial conclusions of how agreement on the benefits may be achieved across the stakeholders.

\section{Theoretical Models of NEC benefits}

Two models of NEC are presented below; the first concerns the critical features associated with NEC-ready systems and the second describes how operational (military) benefits will be realised through better information management. The empirical results collected at the benefits workshop will be related to these models in the analysis that follows.

\subsection{Model of NEC-readiness}

The NECTISE programme (http://www.nectise.com) developed a model of NEC readiness through a set of critical features (termed NEC readiness themes) that inform the systems of systems engineering applicable to development of NEC-ready systems. If agility is the overall aim, then there are enablers and barriers associated with the other themes of interoperability, availability, affordability, dependability and their various interactions. Placing agility in the centre of the model has the meaning that agility is crucial for the success of military operations and is supported through highly interoperable systems and collaboration. 


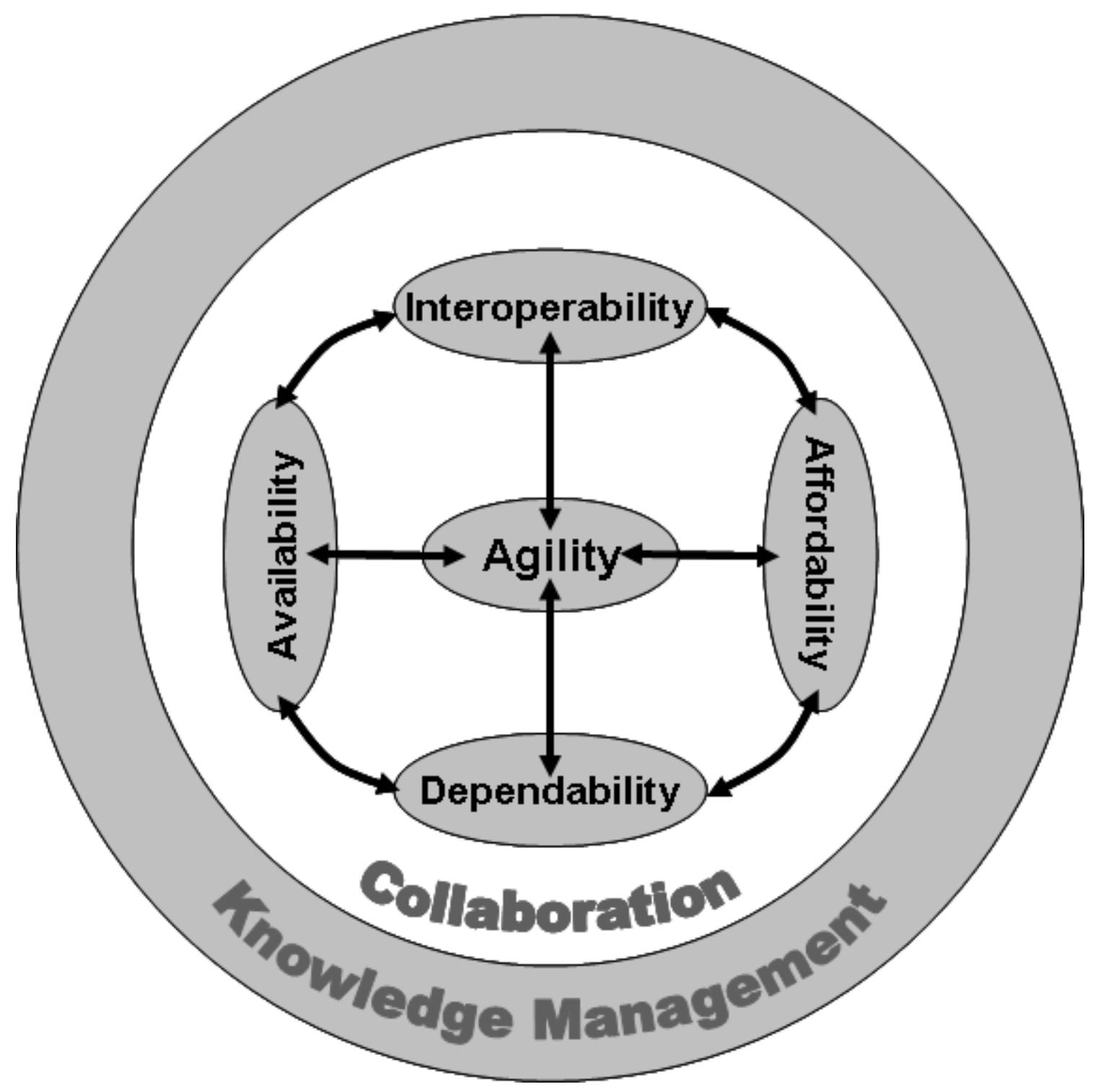

Figure 1: NEC Readiness Themes

Information and knowledge shared/exchanged are also essential to support agile and interoperable complex systems including military organisations and enterprises. The main objectives of agility are to achieve robustness, resilience, flexibility, responsiveness and adaptation.

Figure 1 shows the model of NEC readiness themes and depicts the interdependence of interoperability, affordability, availability, and dependability that critically determine the agility of NEC. These features or themes run through every stage of the capability lifecycle ${ }^{16}$. 


\subsection{NEC Benefits Chains}

The benefits chain represented in Figure 2 was developed by DSTL ${ }^{17}$ by taking the benefits map proposed in the US NCW Conceptual Framework and mapping it onto the UK command and battle space management building blocks. The benefits chain is described through the following assumptions from an initial benefits chain

1. that a robustly networked force should improve the quality of shared information;

2. that this should lead to an increase in Shared Situational Awareness and mutual understanding through enhanced quality of interactions and collaborative planning processes. This, in turn, should enable improvements to the quality and timeliness of decision-making, leading to synchronised/agile actions, resulting in more timely and appropriate effects.

These initial assumptions were tested "using the UK's collection of quantified evidence of the benefits and risks of NEC. This process has led to a modified benefits chain that is presented in figure 2 and which is more fully supported by the evidence" ${ }^{\prime 18}$. The original benefits chain does not consider that:

1. Quality of network has not directly determined the quality of shared information and therefore it must be complemented with the ability to share information.

2. Quality of information and intelligence is an additional factor in the quality of shared information.

3. The ability to adapt $\mathrm{C} 2$ processes is an additional factor in achieving synchronisation of actions defined also as self synchronicity.

4. The new introduced "Right People" building block is related to the training and best practices in order that NEC benefits to be achieved. 




Figure 2: NEC Modified Benefits Chain (from Court ${ }^{19}$ )

Court $^{20}$ provided a series of examples proving the validity of the benefits chain and commented on the validity of the benefits chain as follows:

NEC as a coherent concept is new, but many of its elements (equipment, processes, structures, and training) have been under analysis for many years. This existing knowledge has been brought together to provide a compendium of quantitative evidence of the benefits and risks of NEC. It is this evidence which has been used to assess the validity of the hypothesis presented in the NEC benefits chain.

There are also approaches that have analysed NEC characteristics, benefits and performances using socio technical systems theory and social network analysis ${ }^{21}$, the outcomes of which have complemented the empirical work on NEC benefits and support, from a theoretical perspective, the validity of Court's benefits chain ${ }^{22}$ and the benefits reported in this paper based on stakeholder views. 


\section{Stakeholder views}

\subsection{Outline of previous empirical investigation into NEC perceptions}

Through a series of interviews, Quintana ${ }^{23}$ concluded in her paper entitled 'is NEC dead?' that if it was not dead, it needed a certain amount of resuscitation! In fact, her main conclusion was that a lack of clarity about the NEC concept had made it difficult for industry to engage with the programme. Subsequently Butler ${ }^{24}$ asserted that NEC is not "dead"; it is still "alive and well", but there are areas of concern, mainly due to the level of resources required, differences in understanding NEC, and training. A later workshop ${ }^{25}$ highlighted some of the features of the organisation of defence acquisition that made it difficult to achieve the holistic view needed for realisation of NEC. This wokshop aimed to address and develop new ways of understanding, managing and utilising NECs under conditions of high variability and low predictability by first capturing stakeholder's perceptions of NEC and associated issues. During the workshop stakeholder's views, ideas, concerns about NEC were captured with respect to the question: What are the perceived barriers and enablers for NEC realization? Inputs were taken from industry, $\mathrm{MoD}$, and independent observers and captured in a high-level concept map reproduced in Figure 3. 


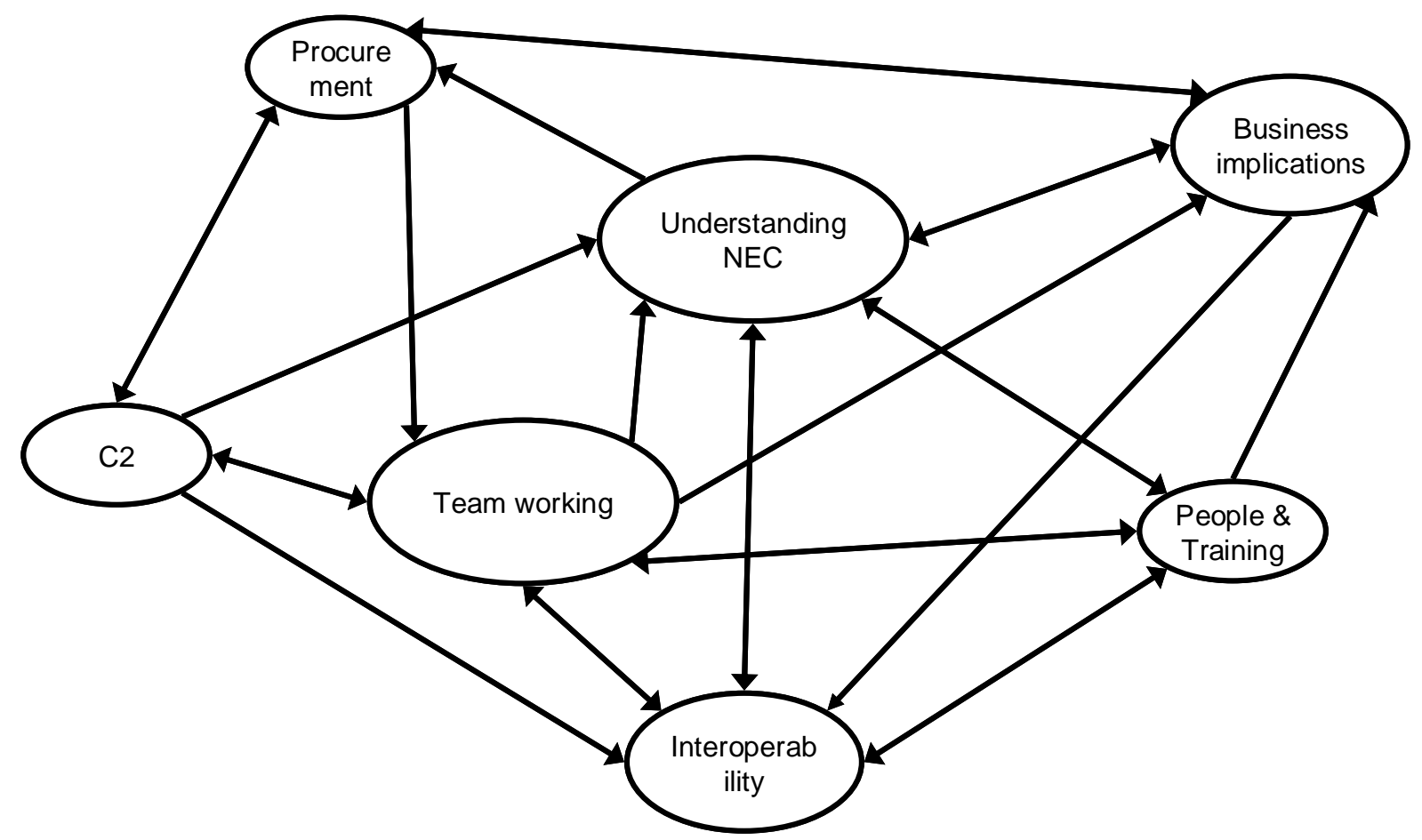

Figure 3: Implications of Understanding NEC (Maytorena, 2008)

In Figure 3, the arrows indicate concepts that were related to each other by the workshop participants; e.g. 'people \& training' led to considerations of 'business implications'. The size of the bubbles indicates the perceived importance of the related concept in understanding NEC. An important implication of this map is that whilst understanding NEC will impact military aspects (C2: command \& control), it will also have a knock-on effect on many aspects of the supply chain. Those effects, and the extent to which they represent benefits or demerits, must be articulated in a way that connects the NEC development community to the military beneficiaries of NEC.

\section{Empirical Research into NEC Benefits}

A multiple perspective analysis (i.e. industry, military and academic/research perspectives) of NEC benefits has been carried out through an interactive workshop conducted to capture, articulate, and then prioritise NEC benefits. The workshop participants are classified as follows: 
Industry - 5 systems engineers in high level decisional positions

Military -4 participants

Civil servant -2 participants

Academics and Researcher: 4 facilitators and 4 participants in the discussions, although they did not vote. The researchers have contributed to the analysis of the workshop outputs and, thus, their theoretical views on NEC impact the study outcomes.

\subsection{Method for running NEC benefits Workshop}



Figure 4: Method used for Workshop Running

The interactive NEC benefits workshop applied a modified mini-delphi strategy $^{26}$ by alternating and combining group discussions and finally drawing consensus conclusions. Essentially this is an epistemological approach to deriving and understanding knowledge on 
NEC benefits. The workshop followed the steps shown in Figure 4. In detail, these were as follows:

A. Participants were divided into two groups of all military and all industrial personnel. The two groups generated a list of twelve benefits each using the template of reflective inquiry questions $^{27}$ shown in Table 1 . The answers to these questions created descriptions of the benefits that were sufficiently detailed to ensure that participants would vote on shared definitions of each benefit.

\begin{tabular}{|l|}
\hline Benefit name \\
\hline What will be different because of NEC in order to generate this benefit? \\
\hline Who are the beneficiaries? (as groups) \\
\hline What benefit is received by each beneficiary? \\
\hline Who delivers, or has delivered, the change that enables the benefit to be realised? \\
\hline Definition of the important terms of a benefits \\
\hline Any context observations \\
\hline
\end{tabular}

\section{Table 1: Benefits Template}

B. First prioritisation: the single transferable vote method was employed for prioritisation using the software system Choice Plus ${ }^{\mathrm{TM}}$. This was chosen as the voting scheme for deriving the ranked lists of benefits to minimise the risk of benefits sought by one group (e.g. industry) being missed from the ranked list because the other group did not recognise them at all. In fact, the results indicated remarkably good agreement between industry and military.

The groups generated their lists independently, but the combined list was presented to all participants to rank their top ten from 1 (most important) to 10 (tenth most important). Any benefits receiving no votes at this stage were removed. Similarly, benefits that were identified independently by the groups, but were agreed to be defined sufficiently closely were united as a single benefit. 
C. The initial groups were disbanded and two new groups formed randomly; these were mixed industrial and military. The groups discussed the lists of benefits and the collective ranking. This provided additional clarification of each benefit and provided the opportunity for participants to share their reasons for ranking one benefit higher than another.

D. The second prioritisation took place using STV using a hidden ballot from which the final ranked list was generated.

E. The top five benefits were presented and discussed in detail in a plenary session.

At each stage, the groups had generated a written record of their deliberations and during this final stage, researchers recorded important points from the discussion to supplement the previously generated information.

\subsubsection{Single Transferable Voting (STV)}

The single transferable voting (STV) approach has a number of advantages. Primarily it minimises wasted votes (compared to a first past the post scheme) and, by using a ranked list of preferences it ensures that popular, but secondary, choices are not lost from the overall ranking of the voters. Each voter ranks his/her top $\mathrm{N}$ preferred candidate (benefits) 1 to $\mathrm{N}$. For each candidate (benefit) the number of $1^{\text {st }}$ choices, followed by $2^{\text {nd }}$ choices, etc. are counted until a winner emerges. Then the winner is removed from the ballot and a $2^{\text {nd }}$ place is determined in the same way, but with the winner's votes now shared among the other candidates according to preference. Full details of the scheme are available from the Electoral Reform society ${ }^{28}$; it is used here to gain a fully representative ranking of benefits across all the stakeholder preferences. 


\section{2 $\quad$ Results}

The initial, complete list of considered benefits and their subsequent ranking (A \& B) is presented in Table 2. This shows how the two groups (industry and military) ranked the benefits; a collective rank is also calculated. The ranking was not revealed to participants during the workshop.

\begin{tabular}{|c|c|c|c|c|}
\hline NEC Benefit Name & $\begin{array}{l}\text { Group } \\
\text { that } \\
\text { generated } \\
\text { benefit }\end{array}$ & $\begin{array}{l}\text { Rank } \\
\text { Collective }\end{array}$ & $\begin{array}{l}\text { Rank by } \\
\text { Industry }\end{array}$ & $\begin{array}{l}\text { Rank } \\
\text { by } \\
\text { Military }\end{array}$ \\
\hline Situational Awareness & Industry & 1 & 1 & \\
\hline Interoperability & Industry & 2 & & 2 \\
\hline Battlespace Management & Industry & 6 & 5 & 4 \\
\hline Cost Effectiveness & Industry & 9 & 10 & 7 \\
\hline Responsiveness & Industry & & & \\
\hline Agility & Industry & 5 & 2 & \\
\hline Improved Control / Effects & Industry & & & \\
\hline Cohesion (on the ground) & Industry & & & \\
\hline Cohesion (strategic / political) & Industry & & 8 & \\
\hline Information Efficiency & Industry & & & 10 \\
\hline Speed of response (Military \& Industry) & Industry & 7 & 6 & \\
\hline Effects Targeting & Industry & & & \\
\hline Location transparency & Industry & & & \\
\hline Resilience & Industry & & 11 & \\
\hline Access to Resources & Industry & & & \\
\hline Ability to predict 'what next' & Industry & & 7 & \\
\hline Better understanding of the 'enemy' & Industry & & & 8 \\
\hline Better Decision making & Industry & 3 & 3 & \\
\hline Representation of Uncertainty & Industry & & & \\
\hline Better resilience & Military & & & \\
\hline
\end{tabular}




\begin{tabular}{|l|l|l|l|l|}
\hline NEC Benefit Name & $\begin{array}{l}\text { Group } \\
\text { that } \\
\text { generated } \\
\text { benefit }\end{array}$ & $\begin{array}{l}\text { Rank } \\
\text { Collective }\end{array}$ & $\begin{array}{l}\text { Rank by } \\
\text { Industry }\end{array}$ & $\begin{array}{l}\text { Rank } \\
\text { by } \\
\text { Military }\end{array}$ \\
\hline Better HF through tailored information & Military & & & \\
\hline Range/ Horizon extension & Military & & & \\
\hline Decision support & Military & & & \\
\hline Service discovery \& tasking & Military & & & \\
\hline Improved decision making & Military & 3 & 4 & 6 \\
\hline Shared situation awareness & Military & 1 & & 1 \\
\hline Co-ordination of effort & Military & 8 & 9 & 5 \\
\hline $\begin{array}{l}\text { Interoperability with other coalition } \\
\text { partners, gov't depts., NGOs, etc. }\end{array}$ & Military & & & 3 \\
\hline Smart use of spectrum & Military & & & \\
\hline Joint working (military) & Military & 4 & & \\
\hline
\end{tabular}

Table 2: Initial list of benefits

The rationalised list was presented to the groups (Table 3, column 1) with situational awareness and shared situational awareness combined as a single benefit. No indication of ranking was provided. This list was the basis for the discussions (C).

\begin{tabular}{|c|c|c|c|c|c|}
\hline \multicolumn{2}{|l|}{ NEC Benefit Name } & $\begin{array}{l}\text { Group } \\
\text { that } \\
\text { generated } \\
\text { benefit }\end{array}$ & $\begin{array}{l}\text { Rank } \\
\text { collective }\end{array}$ & $\begin{array}{l}\text { Rank by } \\
\text { Industry }\end{array}$ & $\begin{array}{l}\text { Rank } \\
\text { by } \\
\text { Military }\end{array}$ \\
\hline Situational Awareness & \multirow[b]{2}{*}{ Combined } & Industry & 1 & 1 & 0 \\
\hline $\begin{array}{l}\text { Shared situation } \\
\text { awareness }\end{array}$ & & Military & 1 & 0 & 1 \\
\hline \multicolumn{2}{|l|}{ Interoperability } & Industry & 2 & 0 & 2 \\
\hline \multicolumn{2}{|c|}{$\begin{array}{l}\text { Interoperability with other coalition } \\
\text { partners, gov't depts., NGOs, etc. }\end{array}$} & Military & 0 & 0 & 5 \\
\hline \multicolumn{2}{|l|}{ Better Decision making } & Industry & 3 & 3 & 0 \\
\hline \multicolumn{2}{|c|}{ Improved decision making } & Military & 3 & 4 & 6 \\
\hline
\end{tabular}




\begin{tabular}{|l|l|l|l|l|}
\hline Joint working (military) & Military & 4 & 0 & 3 \\
\hline Agility & Industry & 5 & 2 & 0 \\
\hline Speed of response (Military \& Industry) & Industry & 7 & 6 & 0 \\
\hline Battlespace Management & Industry & 6 & 5 & 4 \\
\hline Co-ordination of effort & Military & 8 & 9 & 0 \\
\hline Cost Effectiveness & Industry & 9 & 10 & 7 \\
\hline
\end{tabular}

Table 3: Rationalised list of benefits

The final ranking of all stakeholders collectively (D) is presented in Table 4. The top five benefits are shown. It is interesting that they form a hierarchy that resembles the recognised benefits chain ${ }^{29}$.

\begin{tabular}{|l|l|l|}
\hline Rank & NEC Benefits & Origin \\
\hline 1 & (Shared) situational awareness & Both \\
\hline 2 & Better / improved decision & Both \\
\hline 3 & $\begin{array}{l}\text { Interoperability with coalition } \\
\text { partners }\end{array}$ & Both \\
\hline 4 & Joint Working & Military \\
\hline 5 & Battle space management & Industry \\
\hline
\end{tabular}

Table 4: Final Ranking of Benefits: Top Five

\subsection{Scope and definition of Prioritised Benefits}

The groups were required to describe the benefits they identified and to indicate both the beneficiaries and the main stakeholders responsible for delivering, or enabling, those benefits (Table 1). In this section, we distill a definition of each benefit from those descriptions; these identify clearly the form of the benefit that stakeholders seek. The wider descriptions of the benefits were shared among the whole workshop prior to the voting, but only the emergent top five benefits (Table 4) are discussed below. 


\subsubsection{Shared situational awareness}

All stakeholders including non-military actors in operations, military personnel, parts of the supply chain associated with support and logistics, civil servants and politicians were believed to benefit from shared situational awareness (SA), in the following ways:

- A tailored view of a single picture extended to minor capabilities (e.g. Royal Fleet Auxiliaries) will de-risk all operations by enabling better understanding of roles and appropriate courses of action to support operations.

- More complete knowledge, information, data will enable better-informed decisionmaking across the spectrum of command from cabinet office down to forces personnel engaged in operations

- In-service information shared with the supply chain will enable better delivery and maintenance of equipment by contractors

- Shared SA through targeted and effective information distribution will improve governance and reduce risks associated with safety and security

It was noted that the mechanisms for effective information sharing must be delivered across the DLoDs by the NEC development community (MoD + Industry). Information sharing itself is, naturally, the delivery responsibility of every stakeholder.

\subsubsection{Improved decision making}

Improved information management in military operations will benefit military commanders by enabling improved decision making in the following manner:

- Timely and accurate information delivered to the right people will enable coherent and co-ordinated activities, thus benefiting military commanders

- Better management of information will lead to greater transparency of decision making 
- Overall, battle management will be improved by better use of information

- Single point, single source information will lead to greater confidence in the information

- Better management and traceability of operational information will lead to improved equipment delivery by industry

The last of these benefits is clearly realised by the entire supply chain. The benefits will be realised if information management systems and information assurance are delivered by the NEC development community (MOD + Industry) and timely, accurate, traceable, trusted information is delivered by all stakeholders. Because of the complex nature of the supply chain, the benefit of more, higher quality, information requires deep knowledge and understanding of the patterns inherent in the information flows to be realized. This emphasizes the importance of joint working, as discussed below

\subsubsection{Interoperability with coalition partners}

The benefits offered by improved interoperability include:

- Interoperability between multiple forces and agencies enables faster, more appropriate operations

- Improved interoperability will reduce the command and control effort required in operations

- Improved interoperability permits greater agility in the formation of ad hoc coalitions

- Widely accepted industry standards will allow 'plug and play' between players (unknown a priori)

- Improved interoperability increases the resilience of capability

- Improved interoperability improves the ability to manage assets in the operational space

- Improved interoperability leads to improved cost effectiveness 
- But, increased interoperability poses additional risks to safety security and governance.

The benefits of improved interoperability are expected to reach from the tactical decision makers up to HM Treasury, and to include both military and civil authorities. Improved interoperability requires delivery across all DLoDs by all stakeholders (including civil authorities Mechanisms for improved interoperability rely on agreed standards and openness together with changed approaches to decision making by operational staff (military and civil)

\subsubsection{Joint Working}

Joint working refers to integrated collaboration across the armed services. The benefit sought includes the ability to call for an effect, rather than a specific capability, where effect is defined as achieving an operational purpose (strategic or tactical). Joint working across services requires a common understanding and common language across those services. All three services will benefit and this should lead to the provision of synergy and therefore better choices; thus fewer errors in the communications chain and less latency in the communications and quicker response. It is also noted that joint working should lead to cost benefits. However, legacy issues tend to confuse the picture with respect to achieving joint working. The achievement of military joint working relies on harmonisation between industry delivering technology and the military developing the doctrine to use it effectively; in turn, this depends on joint working in industry, more usually referred to as partnering.

In fact, joint working, in the sense of collaborative working, needs to be pervasive throughout the whole effect delivery chain to achieve the agility that is sought by NEC.

\subsubsection{Battle Space Management}

The benefit sought, in terms of battle space management, is to improve decision making through better situational awareness; this is directed towards improved coherence, agility, effectiveness, interoperability, resilience of capability, and cost. It provides faster, more 
appropriate operations in terms of tempo (military) and time to support (industry/military). Improved battle space management is reliant on quality and relevance of information and knowledge. The benefit will be an improved ability to manage assets within the operational space.

\section{$5 \underline{\text { Discussion }}$}

The top five benefits, ranked in Table 4 above, are consistent with the projected benefits originally proposed in the NEC benefits chain ${ }^{30}$. Situational awareness is the most highly regarded benefit though, interestingly, it is the improved situational awareness of so-called disadvantaged units that was chiefly sought. The other benefits of improved decision making, interoperability with coalition partners, joint working and better battle space management can be viewed as a hierarchy in terms of benefits, each following from the one above it. In some ways, an exercise that confirms the priority of benefits to be those that were originally planned for is uninteresting. But it is important to note that although the exercise sought to identify benefits to industry, the resulting consensus - arrived at by both industry and military participants - was consistent with the original operational benefits. The close alignment between stakeholders implies that the benefits previously identified by industry were essentially the operational benefits to the military, rather than benefits to industry alone. During discussion, one senior industrialist remarked that "NEC provides no real benefits to industry, but if that is what the customer requires, then industry will meet that requirement." Nevertheless, the provision of better operational information for the supply chain, as a means of improving both service support and new equipment, was also noted.

Analysis of the workshop outputs implies, unsurprisingly, that interoperability is a key component of improved military capability through better use of information and knowledge 
and that adequate support to command and control requires faster capture, processing, or reuse of time sensitive information. These are rather obvious conclusions, but the coherence between the views of the military and industrial stakeholders, in this study, on the benefits and means to realise them should presage a good prospect of industry creating and supporting appropriate systems to realise the NEC benefits sought by the military. However, understanding the benefits and delivering systems through which they are realised in a commercially viable fashion is not the same thing. The need, then, for metrics through which the benefits can be realistically measured so that improvements can be quantifiably assessed and the investment in research, development and building of NEC-ready systems justified such that industry can be appropriately rewarded for improvements in operational effectiveness is urgent. The derivation of such metrics against the five benefits confirmed in this paper is, thus, an important research activity in its own right.

\section{Conclusion}

A mini-delphi technique has been applied, using a single transferable voting procedure, to reach a consensus on the priority benefits of NEC among a mixed group of industry systems engineers, civil servants from defence, and serving military. The five priority benefits identified by this group were consistent with those projected in the published NEC-benefits chain and are operational in nature. Whilst this confirmation is not a particularly exciting result in terms of new information, it is important to note that despite an endeavour of the workshop being to identify complementary benefits to industry, none were considered by the whole group to be a higher priority than the original five of the benefits chain. It is important that appropriate metrics are devised for these benefits so that improvements can be quantified and so that the industry contribution to NEC-ready systems can be rewarded acordingly. 


\section{Acknowledgements}

The research reported in this paper has been partly funded by BAE Systems and the UK Engineering and Physical Sciences Research Council (EPSRC) under grant number EP/D505461/1 for the project "Network Enabled Capability Through Innovative Systems Engineering (NECTISE)". The authors also acknowledge the contributions and comments of the NEC benefits workshop participants and facilitators. In particular, we are gratefully to Kate Gill, Elizabeth Quintana, Kirsty Brown, Murray Sinclair, Esmond Urwin, Tim Mackley, Andrew Daw and David Gunton. We express our gratitude to Eunice Maytorena for helpful comments and the provision of results from the NEC perspectives workshop (Figure 3).

\section{References}

1 C.D.Blair, J.T. Boardman, and B.S. Sauser, Communicating Strategic Intent with Systemigrams: Application to the Network-Enabled Challenge, INCOSE Journal of Systems Engineering, Wiley Interscience, 10(4), 2007, pp.309-322.

2 E. Quintana, "IS NEC Dead?" An Analysis of Industry's Perspective on the UK's NEC Programme, RUSI Paper, 2007.

${ }^{3}$ S. Michell, ed. NEC - Understanding Network Enabled Capabilities, UK Ministry of Defence, 2009.

${ }^{4}$ UK Ministry of Defence (UK MoD), Network enabled capability, Joint Service Publication (JSP) 777 Edn 1, Ministry of Defence, London, 2005, p. 8.

${ }^{5}$ Ministry of Defence, Delivering Security in a Changing World: Defence White Paper, Cm 6041-I, December 2003, p.3

${ }^{6}$ Op. cit., p. 2.

${ }^{7}$ Op. cit., p. 8.

${ }^{8}$ D.S. Alberts and R.E. Hayes, Power to the Edge, CCRP, Publications Series, 2005, pp. $107-$ 21

${ }^{9}$ A. Borgu, The Challenges and Limitations of 'Network Centric Warfare' - The initial views of an NCW sceptic, Network Centric Warfare 2003 Conference, $17^{\text {th }}$ Sept., www.aspi.org.au/pdf/ncw_ab.pdf 
10 A. Borgu, Network Centric Warfare and Military Operations Other Than War: Counterinsurgency in the 21st century, Network Centric Warfare 2004 Conference, 24-25 Nov., www.aspi.org.au/pdf/NCW_ADF_Nov04_AB.pdf

${ }^{11}$ C. Boyd, W. Williams, D. Skinner and S. Wilson, A Comparison of Approaches to Assessing Network-Centric Warfare (NCW) Concept Implementation, Systems Engineering / Test \& Evaluation (SETE05), Brisbane, Australia, 2005, available: http://www.concepts.aero/documents/NPI-SETE-2005.pdf, last access July 2009

${ }^{12}$ UK Ministry of Defence (UK MoD). Part 1 - Background and Programme of Work, NEC Outline Concept, DSTL/IMD/SOS/500/2, Issue 2.0, 2 May 2003, available: http://www.iwar.org.uk/rma/resources/uk-mod/NEC-Outline-Concept-Pt-1-i2-0.pdf

${ }^{13}$ M.J.D. Henshaw and E.N. Urwin, Demonstrating through-life and NEC requirements for defence systems, NATO Symposium on Decision Support Methodologies for Acquisition of Military Equipment, RTO-SAS-080, Brussels, 22-23 October 2009., p. 2.

${ }^{14}$ Op. cit., p. 1.

${ }^{15}$ MOD, 2005, p. 8.

${ }^{16}$ A.V. Pearce and M.J.D. Henshaw, NEC - More than USB, in The System, 2008, Iss. 18, http://www.seic-loughborough.com/pdf/thesystem-issue18.pdf

17 Court, G., Validating the NEC Benefits Chain, 11 ${ }^{\text {th }}$ ICCRTS, Cambridge, 2005, http://www.dodccrp.org/events/11th_ICCRTS/html/papers/155.pdf, p.8.

${ }^{18}$ Ibid, p. 8.

${ }^{19}$ Ibid, p. 8.

${ }^{20}$ Ibid, pp. 3-7.

${ }^{21}$ G. H. Walker, N. A. Stanton, P. M. Salmon and D. P. Jenkins, A review of socio technical systems theory: a classic concept for new command and control paradigms, Theoretical Issues in Ergonomics Science, Taylor \& Francis, 9(6), 2008, pp. 479-99.

${ }^{22}$ Op. cit., p. 8.

${ }^{23}$ Op. cit., pp. 7-8.

${ }^{24}$ S. Butler, Network Enabled Capability: Alive and Well in the MoD, RUSI Defence Systems, RUSI Paper, 2008, pp. 40-43.

${ }^{25}$ E. Maytorena-Sanchez, 2007, NECTISE workshop, hitherto unpublished results.

${ }^{26}$ K.C. Green, J.S. Armstrong, and A. Graefe, Methods to Elicit Forecasts from Groups: Delphi and Prediction Markets Compared. MPRA Paper No. 4999, Nov. 2007, http://mpra.ub.uni-muenchen.de/4999/1/MPRA_paper_4999.pdf, P. 3.

${ }^{27}$ Bolton, G., Reflective practice - Writing and professional development, Sage Publications Ltd., 2005.

${ }^{28}$ Electoral Reform Society: http://en.wikipedia.org/wiki/Electoral_Reform_Society 
${ }^{29}$ UK MOD, 2005, p. 8.

${ }^{30}$ Court, 2005, p. 8. 